03

\title{
Влияние наножидкостей на теплопередающую способность миниатюрных термосифонов для охлаждения электроники
}

\author{
() Б.И. Бондаренко ${ }^{1}$, В.Н. Морару ${ }^{1, \uparrow, ~ В . Ю . ~ К р а в е ц ~}{ }^{2}$, Г. Бехмард ${ }^{2}$ \\ ${ }^{1}$ Институт газа НАН Украины, Киев, Украина \\ ${ }^{2}$ Национальный технический университет Украины „Киевский политехнический институт“, Киев, Украина \\ ฯE-mail: vasily.moraru@gmail.com
}

Поступило в Редакцию 13 июня 2018г.

В окончательной редакции 21 декабря 2018 г.

Принято к публикации 21 декабря 2018 г.

\begin{abstract}
Приготовлены стабильные наножидкости на основе углеродной сажи DG-100 и углеродных нанотрубок и изучено их влияние на максимальную теплопередающую способность и термическое сопротивление миниатюрных двухфазных термосифонов закрытого типа, применяемых для охлаждения электронных устройств. Получено более чем двукратное повышение теплопередающих характеристик термосифонов при резком снижении их термического сопротивления. Предполагается, что значительно более высокая теплопередача таких термосифонов по сравнению с теплопередачей термосифонов, заправленных водой, объясняется не только более высокой теплопроводностью теплоносителя, но и возникновением своеобразной пористой структуры, препятствующей появлению паровой пленки и усиливающей кипение.
\end{abstract}

DOI: 10.21883/PJTF.2019.06.47503.17424

Одними из эффективных элементов систем охлаждения, использующих принцип испарительно-конденсационного цикла, в настоящее время являются миниатюрные замкнутые двухфазные термосифоны (ДТС) различных конструкций [1-3]. Они отличаются высокими теплопередающими характеристиками и простотой изготовления. Благодаря таким преимуществам ДТС находят широкое применение для охлаждения микроэлектронного оборудования. Помимо всех определяющих факторов (количество заправленного теплоносителя, общая длина, длины зон нагрева (испарения) и конденсации) их важнейшими параметрами являются внутренний диаметр термосифона $\left(d_{i n t}\right)$ и теплофизические свойства теплоносителя. Поскольку уменьшение внутреннего диаметра термосифона существенно снижает его теплопередающие характеристики, значительного повышения производительности ДТС можно добиться за счет улучшения теплофизических свойств теплоносителя, которые влияют на величину максимального теплового потока и температурный режим термосифона. Использование в качестве теплоносителей наножидкостей (НЖ) или обычных жидкостей с добавками небольшого количества нанопорошка позволяет повысить величину критического теплового потока при кипении в некоторых случаях в несколько раз [4-7].

Весьма перспективный способ интенсификации теплообменных процессов заключается в увеличении теплопроводности теплоносителя (жидкости) путем добавления в него твердых наночастиц с высокой теплопроводностью, т.е. в использовании высоко- теплопроводящих НЖ [4,5]. Под термином „наножидкость“ принято понимать коллоидный раствор, состоящий из базовой жидкости и дисперсных наночастиц с характерными размерами от 1 до $100 \mathrm{~nm}$. В качестве базовых жидкостей могут быть использованы вода, органические жидкости и полимерные растворы. Твердыми наночастицами обычно являются частицы химически устойчивых металлов и их оксидов. Только сравнительно недавно появились публикации по исследованию и использованию НЖ на основе углеродных нанотрубок (УНТ), которые дают наибольший эффект в повышении коэффициента теплоотдачи и критического теплового потока [5]. Отличительными особенностями УНТ являются высокая теплопроводность $(2000-3000 \mathrm{~W} /(\mathrm{m} \cdot \mathrm{K}))$ и высокий коэффициент анизометрии. Их диаметр колеблется от одного до нескольких десятков нанометров, а длина может достигать десятков, сотен и даже тысяч микрометров [4].

Вопросам применения наножидкостей в качестве теплоносителей для термосифонов посвящено пока небольшое число работ [8-12]. Их результаты свидетельствуют о том, что добавки нанопорошков к водному теплоносителю способствуют увеличению интенсивности теплоотдачи в зоне нагрева по сравнению с чистой водой. При этом лучшие результаты наблюдались при добавлении в воду порошков оксидов титана и меди (по сравнению с $\mathrm{Al}_{2} \mathrm{O}_{3}$ ). В работах $[11,12]$ показано, что добавление в воду частиц нанопорошков приводит к значительному снижению термического сопротивления и улучшению теплопередающих характеристик таких ДТС. Существенное влияние также оказывает содержание нанопорошков в базовой жидкости. Вероятно, существует некоторая оптимальная концентрация нанопорошка в теплоносителе, при которой наблюдаются максимальные теплопередающие характеристики ДТС.

Разработке ДТС в настоящее время посвящено значительное число работ, анализ которых показывает, что проблема создания миниатюрных испарительно-конденсационных систем с оптимальными характеристика- 


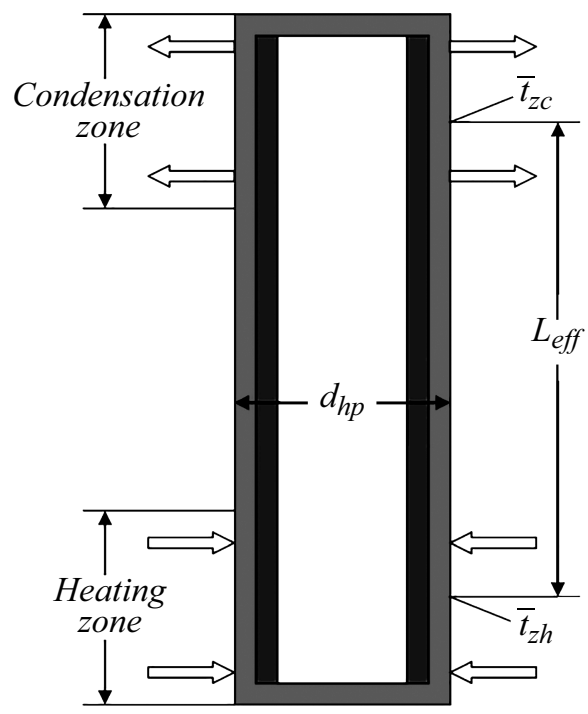

$a$

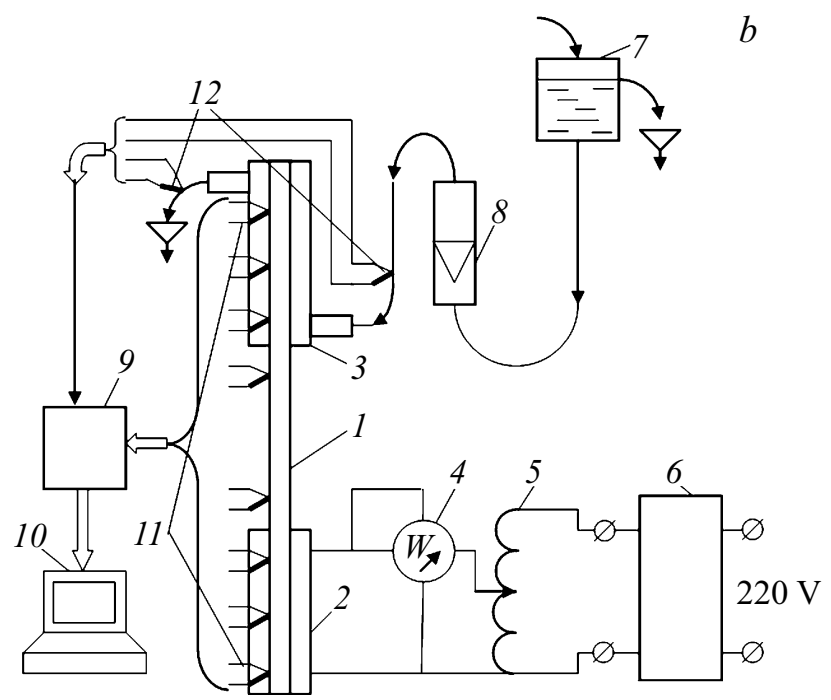

Рис. 1. $a-$ конструкция и схема работы замкнутого двухфазного термосифона: $L_{e f f}-$ эффективная длина термосифона, $d_{h p}-$ его внешний диаметр, $\bar{t}_{z h}, \bar{t}_{z c}-$ средние температуры зон нагрева и конденсации; $b-$ схема экспериментальной установки: 1 - термосифон, 2 - омический нагреватель, 3 - конденсатор типа „труба в трубе“, 4 - ваттметр, 5 - лабораторный автотрансформатор, 6 - стабилизатор напряжения, 7 - бак напорный, 8 - ротаметр, 9 - аналогоцифровой преобразователь, 10 - персональный компьютер, 11 - медь-константановые термопары для контроля температуры термосифона (8 шт.); 12 - медь-константановые термопары охлаждающей воды (2 шт.).

ми решена далеко не полностью, а по ряду вопросов информация недостаточна или вообще отсутствует. Этот пробел усугубляется и большим разбросом в экспериментальных данных различных исследователей.

Цель настоящей работы - изучить и выяснить влияние таких определяющих факторов, как природа теплоносителя и коэффициента заполнения $K_{f}$ термосифонов, на их теплопередающие характеристики.
На рис. 1, a схематически показаны конструкция и схема работы ДТС, а в табл. 1 даны геометрические характеристики исследуемых термосифонов. Коэффициент заполнения $K_{f}$, равный отношению объема, занимаемого теплоносителем $V_{l}$, к объему всей зоны нагрева $V_{z h}$, варьировался от 0.44 до 1.93 . В процессе экспериментов угол наклона термосифонов к горизонту не изменялся и составлял $90^{\circ}$.

В качестве теплоносителей использовались дистиллированная деаэрированная вода и две водноуглеродсодержащие наножидкости, полученные путем ультразвукового диспергирования соответствующих нанопорошков в растворе лигносульфоната натрия. Их характеристики приведены в табл. 2.

Исследования проводились на экспериментальной установке, схема которой приведена на рис. $1, b$. К зоне нагрева (испарения) термосифона тепловой поток подводился с помощью омического нагревателя 2, подключенного к лабораторному трансформатору 5 через стабилизатор напряжения 6. Контроль величины тепловой нагрузки осуществлялся с помощью ваттметра 4. Температура по всей длине термосифона измерялась с помощью медь-константановых термопар, которые были припаяны к внешней стенке термосифона. Сигнал от термопар 11, 12 подавался на аналого-цифровой преобразователь 9 и далее на персональный компьютер 10. Система опроса показаний термопар позволяла фиксировать температуру в реальном времени с частотой $1 \mathrm{~Hz}$.

Для исключения тепловых потерь в окружающую среду термосифон полностью теплоизолировался базальтовым волокном с коэффициентом теплопроводности $0.04 \mathrm{~W} /(\mathrm{m} \cdot \mathrm{K})$. Отвод теплоты в верхней части термосифона осуществлялся с помощью конденсатора типа „труба в трубе“ 3. Зона конденсации омывалась водой с температурой $20^{\circ} \mathrm{C}$ и расходом $G=4.9 \cdot 10^{-3} \mathrm{~kg} / \mathrm{s}$, который поддерживался постоянным с помощью напорного бака 7 и контролировался ротаметром 8. Температура воды на входе в конденсатор и на выходе из него измерялась двумя медь-костантановыми термопарами 12. Температура воды на входе в конденсатор во время эксперимента поддерживалась постоянной с точностью $\pm 0.5^{\circ} \mathrm{C}$ с помощью электронагревателя (на схеме не показан).

По показаниям термопар $12\left(t_{\text {in }}, t_{\text {out }}\right)$, ротаметра 8 и при известной удельной теплоемкости воды $C_{p}$ рассчитывался реальный отводимый термосифоном тепловой поток $Q_{t f}$ (т.е. $Q_{\text {transfer }}$ ) по зависимости

$$
Q_{t f}=C_{p} G\left[\bar{t}_{\text {out }}(\tau)-\bar{t}_{\text {in }}(\tau)\right]
$$

где $t_{\text {out }}(\tau), \bar{t}_{\text {in }}(\tau)$ - средние во времени температуры выходящей и входящей воды в конденсаторе при установившемся режиме теплопередачи в термосифоне.

Коэффициенты теплоотдачи в зонах нагрева (испарения) $\alpha_{z h}$ и конденсации $\alpha_{z c}$ определялись по 
Таблица 1. Геометрические характеристики исследуемых термосифонов

\begin{tabular}{c|c|c|c|c|c|c}
\hline $\begin{array}{c}\text { Внутренний диаметр } \\
d_{\text {int }}, \mathrm{mm}\end{array}$ & $\begin{array}{c}\text { Общая } \\
\text { длина } \\
l_{\Sigma}, \mathrm{mm}\end{array}$ & $\begin{array}{c}\text { Длина зоны } \\
\text { испарения } \\
l_{z h}, \mathrm{~mm}\end{array}$ & $\begin{array}{c}\text { Длина зоны } \\
\text { конденсации } \\
l_{c}, \mathrm{~mm}\end{array}$ & $d_{i n t} / l_{z h}$ & $\begin{array}{c}\text { Коэффициент } \\
\text { заполнения, } \\
K_{f}\end{array}$ & $\begin{array}{c}\text { Материал } \\
\text { стенки } \\
\text { термосифона }\end{array}$ \\
\hline 5 & 700 & $50-200$ & 210 & $0.025-0.1$ & $0.44-1.93$ & Медь
\end{tabular}

Таблица 2. Некоторые характеристики изучаемых наножидкостей

\begin{tabular}{c|c|c|c|c|c}
\hline Наножидкость & $\begin{array}{c}\text { Твердая фаза } \\
\text { наножидкостей }\end{array}$ & $\begin{array}{c}C_{s}, \\
\text { mass } \%\end{array}$ & $\begin{array}{c}r_{a v}, \\
\mathrm{~nm}\end{array}$ & $\begin{array}{c}\sigma, \\
\mathrm{mN} / \mathrm{m}\end{array}$ \\
\hline $4-1$ & $\begin{array}{c}\text { Многослойные } \\
\text { углеродные нанотрубки } \\
(d \approx 10-20 \mathrm{~nm}, \\
6-1\end{array}$ & 0.10 & $410-590$ & $250-500$ & 71.4 \\
& $\begin{array}{c}l \approx 5-10 \mu \mathrm{m}) \\
\text { Аморфный углерод } \\
\text { DG-100 }\end{array}$ & 0.31 & $100-150$ & $2-5$ & 69.8 \\
\hline
\end{tabular}

Примечание. $C_{s}$ - концентрация твердой фазы, $r_{a v}-$ средний эффективный размер частиц в НЖ, $k-$ коэффициент анизометрии частиц, $\sigma$ - поверхностное натяжение при $20^{\circ} \mathrm{C}$.

соотношениям

$$
\begin{aligned}
& \alpha_{z h}=Q_{t f} /\left(\bar{t}_{z h}-\bar{t}_{z t r}\right) S_{z h}=q_{z h} /\left(t_{z h}-\bar{t}_{z t r}\right), \\
& \alpha_{z c}=Q_{t f} /\left(\bar{t}_{z t r}-\bar{t}_{z c}\right) S_{z c}=q_{z c} /\left(\bar{t}_{z t r}-\bar{t}_{z c}\right),
\end{aligned}
$$

где $t_{z h}, \bar{t}_{z t r}, \bar{t}_{z c}-$ средние температуры зон нагрева, транспорта и конденсации, $S_{z h}, S_{z c}$ - площади внутренней поверхности зоны нагрева и конденсации.

По известным значениям средних температур в зонах нагрева и конденсации, а также величине реального передаваемого теплового потока рассчитывалось значение термического сопротивления $R$

$$
R=\Delta t / Q_{t f}=\left(\bar{t}_{z h}-\bar{t}_{z c}\right) / Q_{t f}
$$

В ходе выполнения работы предполагалось, что температуры наружной и внутренней стенок термосифона были равны. Поскольку в качестве материала стенок термосифонов была выбрана медь, абсолютная погрешность определения температуры внутренней стенки даже при максимальных тепловых потоках не превышала $0.05^{\circ} \mathrm{C}$. Температура насыщения жидкости $T_{s}$ определялась по данным термопар в адиабатной зоне.

Наши исследования показали, что характер процессов теплопередачи таких термосифонов с наножидкостями практически не отличается от такового для термосифонов с другими теплоносителями. При увеличении теплового потока термическое сопротивление ДТС уменьшается и зависит от коэффициента заполнения $K_{f}$ (рис. 2,a). Отличие заключается только в количественных характеристиках. В диапазоне исследованных значений коэффициента заполнения $\left(K_{f}\right)$ термическое сопротивление уменьшается, а тепловой поток возрастает с уменьшением $K_{f}$. Вероятно, что максимум $Q$ и минимум $R$ должны наблюдаться при значениях $K_{f} \leqslant 0.45$, так как большее увеличение $K_{f}$ приводит к снижению $Q_{\max }$ (рис. $2, b)$. Дальнейшие исследования позволят уточнить оптимальный $K_{f}$.

Из рис. 2, $b$ также следует, что на максимальный тепловой поток существенно влияет не только коэффициент заполнения ДТС, но и природа теплоносителя. По сравнению с водой лучшие теплопередающие характеристики показал термосифон с наножидкостью на основе углеродных нанотрубок (4-1). При низких $K_{f} \sim 0.5$ значение $Q_{\max }$ увеличивается в 2 раза. Если $K_{f}>1$, то этот показатель $\left(Q_{\max }\right)$ уменьшается. Для НЖ на основе аморфного углерода (6-1) уже при $K_{f} \approx 1.5$ показатель $Q_{\max }$ приближается к таковому для воды (рис. 2, $b$ ).

Сравнение кривых 2 и 3 на рис. 2, $b$ показывает, что, несмотря на меньшую концентрацию, НЖ 4-1 с углеродными нанотрубками может передавать гораздо больший тепловой поток по сравнению с НЖ 6-1 на основе аморфного углерода. В первую очередь это связано с более высокой теплопроводностью и анизометрией наночастиц УНТ по сравнению с таковыми для аморфного углерода DG-100.

На рис. 3, а сопоставлены зависимости коэффициента теплоотдачи в зоне нагрева от плотности передаваемого теплового потока для двух термосифонов: с водой и НЖ 4-1 на основе углеродных нанотрубок.

Из рис. 3, $a$ видно, что до плотностей теплового потока порядка $25 \mathrm{~kW} / \mathrm{m}^{2}$ интенсивность теплоотдачи для воды и наножидкости практически совпадает. Однако при дальнейшем повышении теплового потока у термосифона с водой наступает кризис теплоотдачи, характеризующийся резким падением коэффициента теплоотдачи и повышением температуры в зоне нагрева. В то же время термосифон с наножидкостью 4-1 продолжает отводить тепловые потоки все большей величины. Кризис теплоотдачи у этого термосифона наступает 
при значении, которое примерно в 2 раза превышает величину, зафиксированную для термосифона с водой. Это свидетельствует о том, что в зоне нагрева при кипении НЖ формируется своеобразная пористая структура, которая не только препятствует слиянию пузырей в сплошную паровую пленку и наступлению кризиса, но и повышает интенсивность теплоотдачи.

Критерием эффективности теплопередающей способности термосифонов может служить эквивалентная теплопроводность $\lambda_{e q}$, которая зависит от передаваемого теплового потока $Q_{t f}$, эффективной длины термосифона $L_{e f f}$ и его внешнего диаметра $d_{h p}$. Расчет $\lambda_{e q}$ проводился по зависимости для стержня согласно гипотезе Фурье [13]:

$$
\lambda_{e q}=4 Q_{t f} L_{e f f} / \pi d_{h p}^{2}\left(t_{z h}-t_{z c}\right) .
$$

Данные расчета представлены на рис. 3, $b$. Как следует из рисунка, применение НЖ 4-1 в качестве
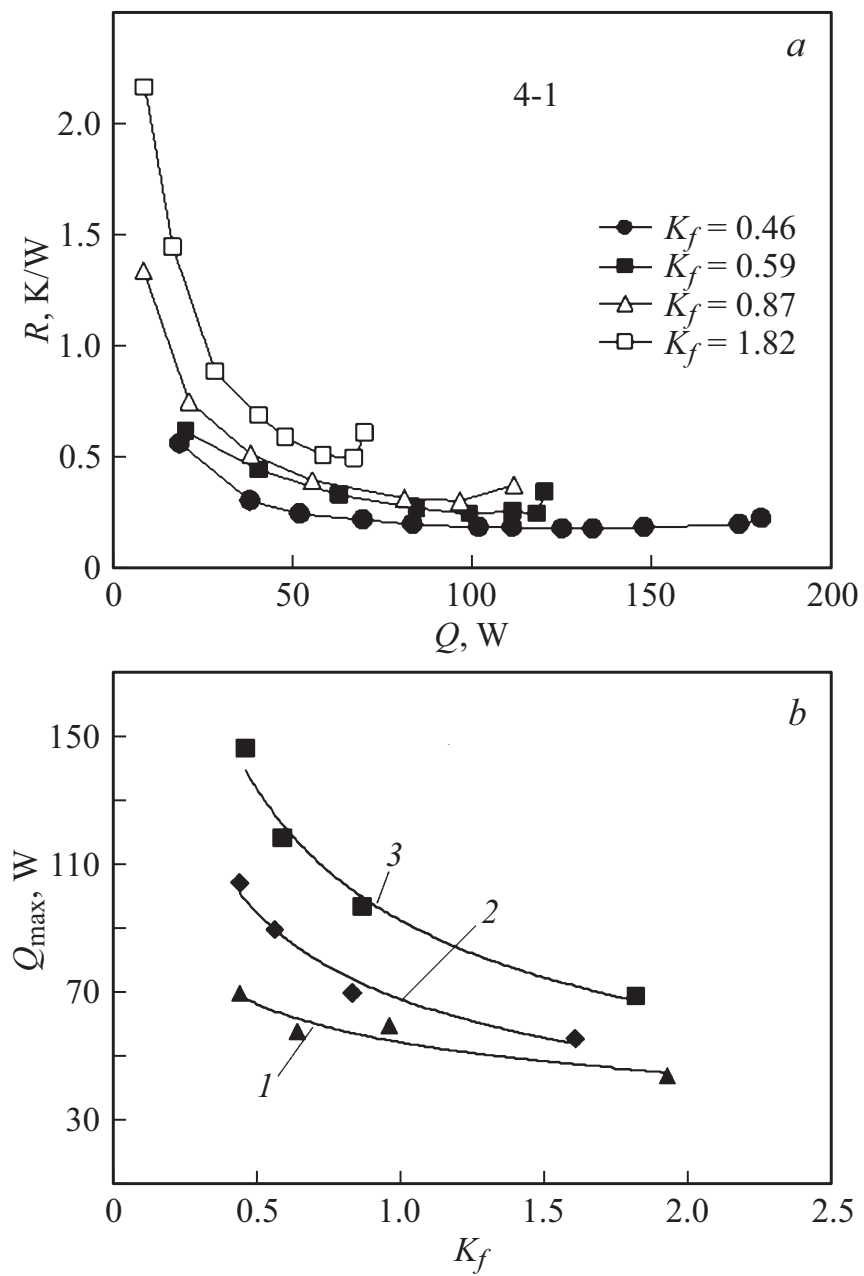

Pис. 2. $a-$ зависимость термического сопротивления от передаваемого теплового потока для термосифона 4-1 при различных заполнениях НЖ на основе углеродных нанотрубок; $b-$ зависимость максимального теплового потока $Q_{\max }$ миниатюрных термосифонов от коэффициента заполнения $K_{f}$ и природы теплоносителя: $1-$ вода, $2-$ НЖ 6-1, $3-$ НЖ 4-1.
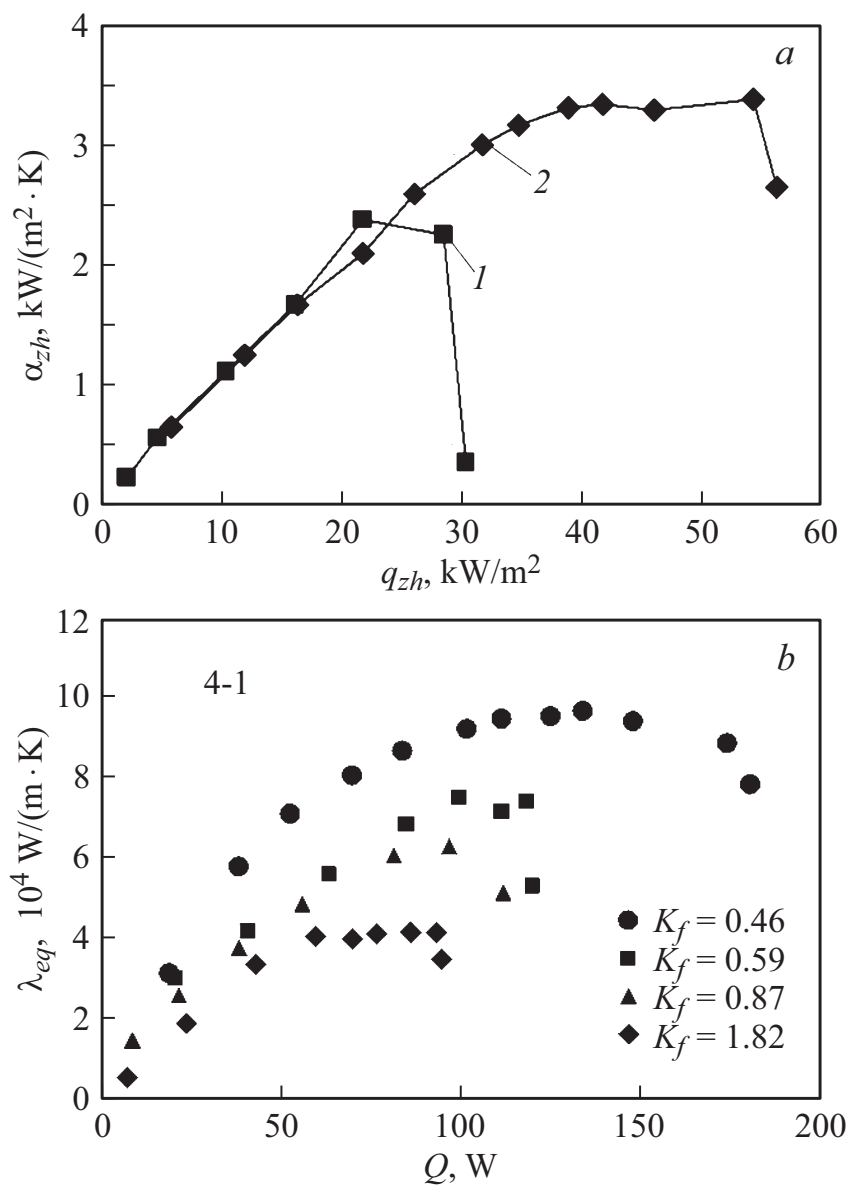

Рис. 3. $a-$ зависимости интенсивности теплоотдачи в зоне нагрева термосифона с водой (1) и термосифона 4-1 (2) при $K_{f}=0.46$ от величины удельного теплового потока в зоне нагрева $\left(q_{z h}\right) ; b-$ зависимости эквивалентной теплопроводности термосифона 4-1 при различных заполнениях от величины передаваемого теплового потока $(Q)$.

теплоносителя термосифонов приводит к поразительному росту эквивалентной теплопроводности вплоть до $10^{5} \mathrm{~W} /(\mathrm{m} \cdot \mathrm{K})$ по мере увеличения отводимого теплового потока. Это свидетельствует о целесообразности широкого применения и дальнейшего изучения подобных испарительно-конденсационных систем охлаждения с УНТ-нанофлюидами, показатели которых значительно превосходят полученные для термосифонов с водой и НЖ другой природы.

\section{Список литературы}

[1] Пиоро Л.С. Двухфазные термосифоны и их применение в промышленности. Киев: Наук. думка, 1988. 136 с.

[2] Безродный М.К., Пиоро И.Л., Костюк Т.О. Процессы переноса в двухфазных термосифонных системах. Теория и практика. Киев: Факт, 2005. 704 с.

[3] Кравец, В.Ю., Письменный Е.Н., Коньшин В.И. // Збірник наук. праць СНУЯЕ та П. Севастополь, 2009. В. 4(32). C. 39-46. 
[4] Das S.K., Choi S.U.S., Yu W., Pradeep T. Nanofluids: science and technology. N.J.: Wiley-Interscience, 2007. 397 p.

[5] Kim H. // Nanoscale Res. Lett. 2011. V. 6. N 1. P. 415.

[6] Бондаренко Б.И., Морару В.Н., Сидоренко С.В., Комыш Д.В., Ховавко А.И. // Письма в ЖТФ. 2012. Т. 38. B. 18. C. $68-78$.

[7] Бондаренко Б.И., Морару В.Н., Сидоренко С.В., Комыш Д.В. // Письма в ЖТФ. 2016. Т. 42. В. 13. С. 32- 43.

[8] Paramatthanuwat T., Boothaisong S., Rittidech S., Booddachan K. // Heat Mass Transfer. 2010. V. 46. N 3. P. 281-285.

[9] Baojin Q., Li Z., Hong X., Yan S. // Energy Convers. Manag. 2009. V. 50. N 9. P. 2174-2179.

[10] Imura H., Kusada H., Oyata J., Miyazaki T., Sakamoto N. // Transact. Jpn. Soc. Mech. Eng. 1977. V. 22. P. 485-493.

[11] Kamyar A., Ong K.S., Saidur R. // Int. J. Heat Mass Transfer. 2013. V. 65. P. 610-618.

[12] Sarathi Shankar K., Suresh Kumar B., Nandhakumar A., Narendhar C. // Int. J. ChemTech Res. CODEN (USA): IJCRGG. 2016. V. 9. N 4. P. 239-247.

[13] Исаченко В.П., Осипова В.А., Сукомел А.С. Теплопередача. М.-Л.: Энергия, 1965. $424 \mathrm{c.}$ 